\title{
Assessment of Knowledge, Attitude and Practice of Disaster Preparedness among Tikur Anbessa Specialized Hospital Health Care Workers, Addis Ababa, Ethiopia
}

\author{
Ashenafi Habte ${ }^{1, *}$, Adamu Addisie ${ }^{1}$, Aklilu Azazh ${ }^{2}$ \\ ${ }^{1}$ Department of Emergency Medicine, Faculty of Medicine, Addis Ababa University, Addis Ababa, Ethiopia \\ ${ }^{2}$ Department of Public Health, Faculty of Medicine, Addis Ababa University, Addis Ababa, Ethiopia
}

Email address:

ashexman2015@gmail.com (A. Habte)

${ }^{*}$ Corresponding author

To cite this article:

Ashenafi Habte, Adamu Addisie, Aklilu Azazh. Assessment of Knowledge, Attitude and Practice of Disaster Preparedness among Tikur Anbessa Specialized Hospital Health Care Workers, Addis Ababa, Ethiopia. American Journal of Nursing Science.

Vol. 7, No. 1, 2018, pp. 39-48. doi: 10.11648/j.ajns.20180701.15

Received: January 4, 2016; Accepted: January 20, 2016; Published: January 31, 2018

\begin{abstract}
Back ground: Disasters are parts of human life; they will never ask for permission to occur in particular area. The world over, they have been caused disastrous complications, disrupting human lives, and exposing the world economy to untold cost. In times of disasters, hospitals are among the most crucial institutions as they are considered as sanctuaries where victims seek ministration. Although major disasters are always to be expected, past disasters and more recent events shows that communities are not yet fully prepared. Objective: The study was intended to assess current awareness, attitude, and practice of the health care workers regarding disaster preparedness and to find out what arrangements were in place should a disaster occur at the hospital. Methodology: The study utilized both quantitative and qualitative research methods. Data collection was made through self-administered questionnaires and semi- structured key informant interview. A total of 290 respondents were participated in the study. Data analysis: Quantitative data were analyzed using descriptive statistics with Epi-info and Statistical Package for Social Sciences (SPSS). Qualitative data were analyzed after organizing into themes and summaries. Result: About half of $(50.8 \%)$ health care workers had good knowledge about hospital disaster preparedness and its plan. The remaining $49.2 \%$ ) had low knowledge. Their general attitude towards the issue was largely positive as $64.8 \%$ of respondents had favorable attitude. Low practice $(8.3 \%)$ of disaster preparedness at the hospital was observed. Moreover, the hospital had neither nor disaster preparedness plan nor other forms of arrangements and preparations for occurrence of disasters. Conclusion and recommendations: The present study found that the health care workers at the hospital had fair awareness and largely positive attitude on disaster preparedness. As the national health policy has not given sufficient attention to hospitals disaster preparedness, there were negligible arrangements in place at the hospital. Therefore, much effort is still expected from all stakeholders including Federal Ministry of Health and managements of hospital.
\end{abstract}

Keywords: Emergencies, Disaster Preparedness, Disaster Preparedness Plan

\section{Introduction}

The world health organization defines the term disaster as "a sudden ecological phenomenon of sufficient magnitude to require external assistance". The JCAHCO has somewhat different definition; which states a disaster as "an imbalance in the availability of medical care and a mal-distribution of medical resources versus casualties within a community" [1]. Now days, marked shift is being made on the way emergencies are managed. In the past times, more emphasis was on humanitarian response, the way emergencies are managed and relief activities than on strategies and actions to mitigate the effects of disasters on communities to preserve lives and assets. Health facilities have symbolic social and political values that contribute to a community's sense of security and wellbeing. As such, hospitals primarily must be 
protected from the avoidable consequences of disasters $[2,3]$.

Although major disasters are always to be expected, past disasters and more recent events demonstrate that communities are still often not fully prepared for dealing with disaster issues. Disasters are certainly parts of our life. They may haphazardly occur in particular area and time. Indeed no one likes to talk about planning for disasters. It is human behavior to say 'it will never happen here'. In reality, however, daily news and reports tell us terrible events can and do happen anywhere, anytime [4]. Reports of the past experiences clamorously speak that hospitals are at risk of structural damage and functional collapse during disaster events. In the occurrences of mass causalities, in particular, they place heavy demands on hospital services. They suffered serious structural damages or collapse depriving of rendering their usual community services including in the occasions of disasters. There are countless cases of health infrastructures from sophisticated hospitals to small but vital health centers that have suffered this fate [5].

Various international policies and frame works advocate disaster preparedness plan for hospitals. Hyogo frame work for action 2005-2015: "hospitals safe from disasters". UNISDR dedicated to the world disaster reduction campaign 2008-2009 with similar theme. WHO/AFRO targeted for all countries to have disaster preparedness plans covering multiple hazards by the year 2013. But, developing culture of preparedness remained a challenge for most national authorities. An important element in maintenance of preparedness is the knowledge and capabilities of health care staffs. Most health care practitioners lacked the knowledge and management skills to deal with disasters [3, 6, \& 7].

The world over, they have been caused disastrous complications, disrupting human lives, \& exposing world economy to untold cost. In the past quarter century, 3.4 million lives have been estimated to be lost. Trillions of dollars in related damages have been lost. In the year 2011 alone, more than 30,773 people were killed. Over 244.7 million others were affected and caused estimated US\$ 366.1 billion economic damages. the problem by far troubling in Africa, because, each year nations in the continent are at increased risk as they are facing an ever growing assortment of hazards more than other continent. Financially, Africa lost USD\$ 15 billion due to emergencies and disasters, in 2007 alone [5].

Over the past four decades, the sub Saharan African countries have experienced thousands of disasters. Each year, the nations in the continent are facing an ever growing assortment of hazards more than other continent. In 2007 alone, the continent lost USD\$ 15 billion due to emergencies and disasters. As a result, the WHO/AFRO target was for all countries to have DRR and emergency preparedness plans covering multiple hazards by the year 2013. Nevertheless, the organization has noted that a number of countries in the region did not have comprehensive emergency preparedness plans. The country was among 20 countries selected by GFDRR due to their high vulnerability to natural hazards and low economic resilience to cope with disaster [5, 8, \& 9].
The issue of disasters is so critical that merit intellectual attention \& resources. However, very little has so far been done in the area of disaster preparedness in Ethiopia. It is with this in mind, that the research was interested to explore mainly Knowledge, attitude and practice health care workers on disaster preparedness. Moreover, the research was intended to find out what arrangements were in place should disaster occur at hospital.

\section{Methods and Materials}

\subsection{Study Area and Study Period}

Ethiopia is one of oldest African country. It is the tenth largest country in Africa, covering 1,104,300 square kilometers and is the major constituent of the landmass known as the Horn of Africa. Geographically, the country is nearest to the great African rift valley and bordered on the north and northeast by Eritrea, on the east by Djibouti and Somalia, on the south by Kenya, and on the west and southwest by Sudan. Its geographical coordinates are between $800 \mathrm{~N}$ and $3,800 \mathrm{E}$. Ethiopia is a country with great geographical diversity and its topography shows a variety of contrasts ranging from high peaks of $4,550 \mathrm{~m}$ above sea level to a low depression of $110 \mathrm{~m}$ below sea level. The predominant climate type is tropical monsoon, with temperate climate on the plateau and hot in the lowlands.

Projections from the 2007 population and housing census estimate the total population for the year 2010 to be 79.8 million. According to 2007 census, the country is among the least urbanized country in the world with $83.6 \%$ living in rural areas whilst $16.4 \%$ of the total population living in urban areas. The largest city in the country is Addis Ababa, the capital, with estimate of 3-4 million people.

This study was conducted in Tikur Anbessa Specialized Hospital. It is found in Addis Ababa city, Kirkos sub city. The hospital is the country's biggest specialized referral hospitals containing around 800 total numbers of beds. This study was conducted from April 1-14, 2013 using the planned research materials supposed to be appropriate to collect the required data.

\subsection{Study Design}

This was hospital based cross-sectional study involving the healthcare workers at Tikur Anbessa specialized Hospital. In order to answer the research questions, meet the study objectives and gain a better understanding of the research problems, the research was focused on collecting and analyzing data by mixing both quantitative and qualitative data through the use of self-administered questionnaires with open and closed ended questions. Likewise, key informant interview with open ended questions was employed.

\subsection{Population}

As source population, this study involved all health care workers at Tikur Anbessa hospital, as all of the workers have a part to play in responding to disasters. The study 
populations were the total sampled units determined using simple proportion sample size calculation formula followed by stratified sampling technique.

Inclusion and exclusion criteria: All Tikur Anbessa Specialized Hospital employees including residents were included in the study. All contractual workers and supportive staffs of the college, undergraduate and post graduates students, Emergency physicians, Emergency Medicine residents, and Emergency master nurses were excluded.

\subsection{Sample Size Determination and Sampling Techniques}

The final sample size was determined using simple proportion formula with 50\% Prevalence, 95\% CI \& 5\% margin error; adjusted to final sample size of 290 . Thereafter, stratified sampling technique was used (Clinical staffs $=137$, Supportive/admin staffs=153). Seven key informant interviewees were purposively selected from member of hospital planning committee, selected heads of departments, and part of hospital management team.

\subsection{Data Collection and Data Quality Control}

A research assistant was recruited to assist with data collection. He was a colleague, who had professional understanding of disaster preparedness and had been involved in simulation activity. He was fluent in the vernacular language. The assistant was trained in order to familiarize him with the distribution and administration of the study instruments as well as in upholding the confidentiality of the respondents. To ensure the quality of data, the questionnaire was pretested prior to start of actual data collection in order to determine validity and reliability; then ongoing supervision was performed by reviewing the data before analysis.

\subsection{Data Processing and Analysis}

Data were cleaned and entered into a computer using EpiInfo version 6.5 statistical programs. Thereafter, data were exported to SPSS version 20.0 for further analysis. Qualitative data from KII was organized into themes and summarized into four sub-topics: policies, hospital disaster plan, and need of vulnerability assessments, training and education.

\subsection{Ethical Considerations}

The research title was approved by Addis Ababa University College of Health Sciences Department of Emergency Medicine. The purpose of the research was explained to the participants, and informed consent was obtained prior to the issuing of questionnaires. All the information gathered from the respondents was kept confidential, and their names were not appeared on the questionnaires. Moreover, letter of permission was issued from Addis Ababa University College of medicine, Department of Emergency Medicine prior to the actual data collection.

\subsection{Limitations of the Study}

Not all the questionnaires were returned; some of the specialists and many of supportive staffs did not return the questionnaire that lowered down the response rate to $80.4 \%$. As some of the questionnaires were incomplete they were discarded which again reduced the expected response rate. Some of the key informants were not comfortable to share their view as required as possible.

\subsection{Operational Definitions}

All-hazard approach - the development and implementation of risk reduction and emergency preparedness strategies for all the hazards in the community

Whole Health Approach - the unification of all emergency preparedness planning and coordination activities for the various health risks in one emergency preparedness and response unit.

Disaster preparedness plan - an agreed set of arrangements for preparing for, responding to, and recovering from emergencies, and involves the description of responsibilities, management structures, strategies, and resource and information management with a view of protecting life, property and the environment.

Good knowledge - Refers to respondents who have scored more than $50 \%$ of knowledge questions.

Low knowledge - Refers to respondents who have scored less than $50 \%$ of knowledge questions.

Negative attitude - Represents those respondents who have scored less than $50 \%$ from attitude question.

Positive attitude - Indicates respondents who have scored greater than or equal to $50 \%$ from attitude questions.

Vulnerability - the level of loss that an element or group of elements: people, structures, goods, services, economic or social capital that are exposed to risk would experience as a result of the probable occurrence of a disastrous event.

\section{Key Findings}

This section focuses on the presentation of key research findings based on the self-administered questionnaire and key informant interviews. The results are presented in the form of texts, tables and figures.

Table 1. Distribution of respondents by their current positions and sex, Addis Ababa, Ethiopia, 2013.

\begin{tabular}{lll}
\hline & Male & Female \\
\hline Specialists & $14(82.4 \%)$ & $3(17.6 \%)$ \\
R Residents & $20(71.4 \%)$ & $8(28.6 \%)$ \\
General practitioners & $12(60.0 \%)$ & $8(40.0 \%)$ \\
Health officer & $2(40.0 \%)$ & $3(60.0 \%)$ \\
Nurses & $20(30.8 \%)$ & $45(69.2 \%)$ \\
Pharmacists & $7(63.6 \%)$ & $4(36.4 \%)$ \\
Laboratory technologists & $8(72.7 \%)$ & $3(27.3 \%)$ \\
Anaesthetists & $8(72.7 \%)$ & $3(27.3 \%)$ \\
Administration & $13(61.9 \%)$ & $8(38.1 \%)$ \\
Others & $23(56.1 \%)$ & $18(43.9 \%)$ \\
Total & $127(55.2 \%$ & $103(44.8 \%)$ \\
\hline
\end{tabular}


Distribution of respondents by their age category: Most of the respondents were in the $20-30$ age groups $(40.9 \%)$. The $31-40$ age groups contributed $37.8 \%$ of the respondents, while those in the $41-50$ age group were $11.3 \%$ and those in the 51-60 age groups were $10 \%$.

Work experience/ duration on current position: Respondents were asked how many years they had worked in their current position. Most of the staff members (48.7\%) worked in their current positions for $1-5$ years while $17.8 \%$ of the respondents worked in their current positions for five to ten years. Respondents who worked in their current position for 10-15 years and 15-20 years were respectively $7 \%$ and $7.4 \%$. Only $6.1 \%$ worked for more than 20 years in their current positions. Respondents who have worked in their position for not more than one year were $13 \%$.

Category of respondents by their duty station at the hospital: Higher proportion (21.7\%) of them worked in the "other" group. Which include Radiology department, the diabetic center, Gastro intestinal unit, Neurology unit, Gynecology unit Nuclear medicine unit, ART clinic, and offices and so forth, followed by those stationed in ward $(20.4 \%)$, then operation room (16.5\%). Those working in outpatients departments and casualty represent $14.8 \%$ and $8.3 \%$ respectively. The other duty stations represented were intensive care unit $(9.1 \%)$, laboratory $(5.2 \%)$, and pharmacy $(3.9 \%)$.

Level of education: Out of total respondents (230), $113(49.1 \%)$ of the respondents had first degree as their highest level of education. Those who had attained post graduate degree education were $47(20.4 \%)$ respondents. Those who had diploma were $45(19.6 \%)$ while those who had primary and secondary school education were $5(2.2 \%)$. None of the respondents were in the "no schooling" category, thus omitted from analysis.

\subsection{Knowledge of Respondents on Disaster and Disaster Preparedness at Tikur Anbessa Hospital}

This section looks at findings from questions provided to assess the respondents' knowledge, awareness and experience concerning disaster and disaster preparedness at their hospital.

While about half $117(50.8 \%)$ of health care workers at the hospital had good knowledge about hospital disaster preparedness and its plan, the remaining 113(49.2\%) had low knowledge. Around $2 / 3^{\text {rd }}$ of the respondents mentioned that they knew the term disaster while $13.7 \%$ of them did not know it. They were further asked whether external assistance is needed or not after an occurrence of a disaster. While $26.5 \%$ had confusion with the term as they said external assistance is not needed after a disaster, $4.8 \%$ were not sure whether or not external assistance is needed. While the main source of information about disaster and its preparedness was books $(50 \%), 16 \%, 12 \%, 10 \%$, and $7 \%$ of respondents obtain information of disasters from television, radio, 'other', and newspaper respectively. The respondents were asked whether they knew what a hospital disaster plan should contain. One hundred thirty six $(59.1 \%)$ of the respondents did not know about what a hospital disaster plan should contain, while $94(40.9 \%)$ of the respondents indicated that they knew what a hospital disaster plan should contain. The following are the contents that the respondents suggested: Preparation of emergency shelters and evacuation systems; identification of hazards through vulnerability assessments. Establishing communication chain with media agencies and relevant institutions; the issues of training, workshops, and education regarding preparation for disasters

Table 2. Distribution of respondents by their awareness on role of hospitals during disasters, Addis Ababa, Ethiopia, 2013.

\begin{tabular}{lll}
\hline & Yes & No \\
\hline Specialist & $17(100.0 \%)$ & $0(.0 \%)$ \\
Resident & $12(42.9 \%)$ & $16(57.1 \%)$ \\
General Practitioners & $13(65.0 \%)$ & $7(35.0 \%)$ \\
Health officer & $4(80.0 \%)$ & $1(20.0 \%)$ \\
Nurses & $33(50.8 \%)$ & $32(49.2 \%)$ \\
Pharmacists & $4(36.4 \%)$ & $7(63.6 \%)$ \\
Laboratory technologists & $6(54.5 \%)$ & $5(45.5 \%)$ \\
Anaesthetists & $7(63.6 \%)$ & $4(36.4 \%)$ \\
Administrations & $5(23.8 \%)$ & $16(76.2 \%)$ \\
Others & $9(22.0 \%)$ & $32(78.0 \%)$ \\
Total & $110(47.8 \%)$ & $120(52.2 \%)$ \\
\hline
\end{tabular}

The table shows that most of the respondents $(78 \%)$ who completed the questionnaire in the 'others' category were not aware of the role of hospitals during disasters. Those who were aware the roles of hospitals were asked to list the roles. The main roles listed by majority of respondents were that of routine treatment of the victims, while some mentioned it as organizing and coordinating all activities, communicating with relevant institution like fire brigade and Red Cross for assistance.

\subsection{Awareness of Respondents on Legislation or Policy That Governs Disaster Preparedness}

Most of the respondents (74.3\%) mentioned that they were not sure whether or not there was legislation or policy that governs disaster preparedness at their hospital. The respondents were further asked how much important to have that. Their majority have mentioned that presence of legislation or policy would have paramount importance. According to them, the hospital should have to have at least a clear guide lines on how to handle both victims of natural or man-made disaster. With this regard, detailed and more emphasized suggestions were obtained from the key informants. As to them, presence of a policy that directs health facilities to mitigate and prepare for disasters is particularly important in connection with current socioeconomic and diplomatic change of Ethiopia. In addition, the other point they mentioned to express the benefit of having disaster policy was the issue of terrorism, which is not only the problem of a single country but also of the globe. They further, mentioned the importance of disaster management policy in relation to the proximity of Addis Ababa to the east African Great Rift Valley, which could bring unusual types of disasters like earth quakes and volcanoes. In general the their view on importance of having disaster policy in health care 
system can be summarized by the speech of one of the informants as: "The presence of such a policy could affect many things; it affects management, budgeting, equipment's and supply; it also entails accountability and responsibility; it, generally, affects the whole system of health care organization". Participants were asked to rate their current knowledge and skills in managing emergencies and disasters. The results are summarized in table below.

Table 3. Knowledge and skills of respondents on management of after a disaster, Addis Ababa, Ethiopia, 2013.

\begin{tabular}{|c|c|c|c|c|}
\hline & Excellent & Good & Fair & Poor \\
\hline Specialist & $6(35.3 \%)$ & $10(58.8 \%)$ & $1(5.9 \%)$ & $0(0 \%)$ \\
\hline R Residents & $1(3.6 \%)$ & $5(17.9 \%)$ & $11(39.3 \%)$ & $11(39.3 \%)$ \\
\hline General practitioners & $0(0 \%)$ & $13(65.0 \%)$ & $5(25.0 \%)$ & $2(10.0 \%)$ \\
\hline Nurses & $10(15.4 \%)$ & $21(32.3 \%)$ & $17(26.2 \%)$ & $17(26.2 \%)$ \\
\hline Pharmacists & $0(.0 \%)$ & $2(18.2 \%)$ & $2(18.2 \%)$ & $7(63.6 \%)$ \\
\hline Laboratory technologists & $0(.0 \%)$ & $2(18.2 \%)$ & $5(45.5 \%)$ & $4(36.4 \%)$ \\
\hline Administration & $0(.0 \%)$ & $0(.0 \%)$ & $0(.0 \%)$ & $21(100.0 \%)$ \\
\hline Others & $0(.0 \%)$ & $1(2.4 \%)$ & $8(19.5 \%)$ & $32(78.0 \%)$ \\
\hline Total & $19(8.3 \%)$ & $61(26.5 \%)$ & $54(23.5 \%)$ & $96(41.7 \%)$ \\
\hline
\end{tabular}

\subsection{Attitudes of the Respondents Towards Disaster Preparedness}

This section is on the attitudes of the Tikur Anbessa Hospital healthcare workers regarding hospital disaster planning. It also highlights the willingness of the healthcare workers to report for duty during infectious disease outbreaks. The respondents in general were presented with various statements were basically aimed at finding out their attitude on disaster plan at the hospital. The general attitude of respondents towards disaster preparedness was largely positive as $150(64.8 \%)$ of respondents had favorable attitude and $70(34.3 \%)$ had negative attitude towards disaster preparedness.

Table 4. Respondents view as to how much Tikur Anbessa hospital was prepared to manage disaster, Addis Ababa, Ethiopia, 2013.

\begin{tabular}{lll}
\hline Response & Frequency & Percent \\
\hline Strongly agree & 19 & 8.3 \\
Agree & 41 & 17.8 \\
Not sure & 58 & 25.2 \\
Disagree & 50 & 21.7 \\
Strongly disagree & 62 & 27.0 \\
Total & 230 & 100.0 \\
\hline
\end{tabular}

The key informants were of the opinion that their hospital was prepared nothing at all. The respondents were asked what they felt about the staff compliment. Majority of them did not think that their hospital had an adequate staff complement to manage disasters. The key informants also confirmed that their hospital was not adequately prepared because they had heavy burden and there was inadequacy of staff. Lack of awareness, of previous exposure of disaster history at the area negligence and were among points mentioned by the key informants.

Attitude of respondents on Vulnerability assessment at the hospital: Views of respondents who filled up the questionnaires on importance of vulnerability assessment are presented in the following tables.

Table 5. Importance of vulnerability assessment at Tikur Anbessa hospital, Addis Ababa, Ethiopia, 2013.

\begin{tabular}{|c|c|c|}
\hline Response & Frequency & Percent \\
\hline Strongly agree & 159 & 69.1 \\
\hline Agree & 53 & 23.0 \\
\hline Not sure & 11 & 4.8 \\
\hline Disagree & 6 & 2.6 \\
\hline Strongly disagree & 1 & 0.4 \\
\hline Total & 230 & 100.0 \\
\hline
\end{tabular}

As presented in table 5, almost 159(69.1\%) and 53(23\%) of the respondents indicated that they strongly agree and agree respectively with the issue of vulnerability assessment at their hospital. All of the key informants strongly recommended that the hospital had to have potential disaster risk profiles.

The respondents were asked to list disasters that they thought likely to occur in their area. This was with the intention of identifying what possible hazards were in the hospital so that they would get meticulous attention. The hazards listed by most of the respondents include road traffic accidents; structural collapse, fire, and disease outbreak were among the main fears of the key informants. Besides, they have also suggested that unusual conditions like terrorist attack, conflict, and earth quake could occur in or around the hospital. Respondents were further asked the likely hood of disasters occurrence at or around the hospital. This was in an effort to determine their attitudes as to whether or not they assume disaster could occur irrespective of place and time. The results are shown in table 6 . 
Table 6. The likelihood of disasters occurrence at/around Tikur Anbessa hospital, Addis Ababa, Ethiopia, 2013.

\begin{tabular}{|c|c|c|c|c|c|}
\hline & Stro. agree & Agree & Not sure & Disagree & Str. disagree \\
\hline Specialists & $0(0 \%)$ & $1(5.9 \%)$ & $1(5.9 \%)$ & $10(58.8 \%)$ & $5(29.4 \%)$ \\
\hline Residents & $2(7.1 \%)$ & $2(7.1 \%)$ & $4(14.3 \%)$ & $7(25.0 \%)$ & $13(46.4 \%)$ \\
\hline General Practitioners & $1(5.0 \%)$ & $3(15.0 \%)$ & $4(20.0 \%)$ & $3(15.0 \%)$ & $9(45.0 \%)$ \\
\hline Health officers & $0(0 \%)$ & $1(20.0 \%)$ & $1(20.0 \%)$ & $2(40.0 \%)$ & $1(20.0 \%)$ \\
\hline Nurses & $9(4.6 \%)$ & $13(20.0 \%)$ & $21(32.3 \%)$ & $15(23.1 \%)$ & $13(20.0 \%)$ \\
\hline Pharmacists & $0(0 \%)$ & $4(36.4 \%)$ & $4(36.4 \%)$ & $3(27.3 \%)$ & $0(0 \%)$ \\
\hline Laboratory technologists & $1(9.1 \%)$ & $4(36.4 \%)$ & $4(36.4 \%)$ & $1(9.1 \%)$ & $1(9.1 \%)$ \\
\hline Administration & $3(14.3 \%)$ & $0(0 \%)$ & $6(28.6 \%)$ & $3(14.3 \%)$ & $9(42.9 \%)$ \\
\hline Others & $7(17.1 \%)$ & $6(14.6 \%)$ & $12(29.3 \%)$ & $6(14.6 \%)$ & $10(24.4 \%)$ \\
\hline Total & $19(8.3 \%)$ & $41(17.8 \%$ & $58(25.2 \%)$ & $50(21.7 \%)$ & $62(27.0 \%)$ \\
\hline
\end{tabular}

The above table indicates that greater proportion of respondents were aware that the hospital could be affected by disasters. All the staff categories had higher proportions of staff that disagreed with the statement. In connection with this, the key informant interviewees were requested their opinion on the question "Should disaster preparedness be peculiarly important for Tikur Anbessa hospital?" Their opinion can be concluded by the quote of one of the key informants as follows. "We have never faced a disaster does not mean there will never be a disaster; rather, it does mean we are fortunately given only one more chance to get ready for... Regardless of place and time, as long as we live in this world of uncertainty, we are certainly at risk of disasters". Same question was also provided for respondents who have filled up the questionnaire. Half of the respondents indicated that TikurAnbessa hospital is peculiarly need to had disaster preparedness plan (strongly agree). In addition, $26.1 \%$ of the respondents were also agreed with the statement. Even though the justification behind was not asked, $9.6 \%$ and 3.9\% of them disagree and strongly disagree with the statement respectively. With regard to responsible body for disaster preparedness, the respondents' attitude is depicted in the following table.

Table 7. Responsibility of disaster preparedness, Addis Ababa, Ethiopia, 2013.

\begin{tabular}{|c|c|c|c|c|c|c|}
\hline \multicolumn{2}{|c|}{ Responsibility of disaster planning } & \multirow{2}{*}{$\begin{array}{l}\text { Strongly agree } \\
32(13.9 \%)\end{array}$} & \multirow{2}{*}{$\begin{array}{l}\text { Agree } \\
27(11.7 \%)\end{array}$} & \multirow{2}{*}{$\begin{array}{l}\text { Not sure } \\
42(18.3 \%)\end{array}$} & \multirow{2}{*}{$\begin{array}{l}\text { Disagree } \\
61(26.5 \%)\end{array}$} & \multirow{2}{*}{$\begin{array}{l}\text { Strongly disagree } \\
68(29.6 \%)\end{array}$} \\
\hline 1 & $\begin{array}{l}\text { Disaster planning is only for hospital's } \\
\text { administrative staffs and heads of departments. }\end{array}$ & & & & & \\
\hline \multirow[t]{2}{*}{2} & $\begin{array}{l}\text { Only doctors and nurses need to know about } \\
\text { disaster plans. }\end{array}$ & $14(6.1 \%)$ & $16(7.0 \%)$ & $31(13.5 \%)$ & $75(32.6 \%)$ & $94(40.9 \%)$ \\
\hline & Total & $46(20 \%)$ & $43(18.7 \%)$ & $75(31.8 \%)$ & $136(59 \%)$ & $162(70.5 \%)$ \\
\hline
\end{tabular}

As showed in table 7, the vast majority of respondents had a view that disaster preparedness concerns every one. There were also respondents who were either not sure or perceived the issue of disaster preparedness as responsibility of limited individuals.

Willingness to receive information, training and education about disaster preparedness: The willingness of respondents to receive disaster related information was asked with intention of determining their attitude towards disaster preparedness. Out of all respondents, 182(79.1\%) of them were willing to receive information regarding disasters and their preparation. Only $48(20.9 \%)$ of them indicated that did not want to the information. Most of the respondents $(53.5 \%$ and $29.6 \%$ strongly agree and agree respectively) indicated that healthcare workers need to had training and education related to disasters and emergencies.

Table 8. Willingness to report in the events of infectious disease outbreak, Addis Ababa, Ethiopia, 2013.

\begin{tabular}{|c|c|c|c|c|c|c|}
\hline No & & Strongly agree & Agree & Not sure & Disagree & Strongly disagree \\
\hline 1 & $\begin{array}{l}\text { I am willing to work even if I am at risk of contracting the } \\
\text { disease. }\end{array}$ & $43(18.7 \%)$ & $88(38.3 \%)$ & $60(26.1 \%)$ & $29(12.6 \%)$ & $10(4.3 \%)$ \\
\hline 2 & $\begin{array}{l}\text { I am confident that the hospital will offer me adequate } \\
\text { protective measures to reduce the risk of contracting the } \\
\text { disease. }\end{array}$ & $14(6.1 \%)$ & $41(17.8 \%)$ & $85(37 \%)$ & $50(21.7 \%)$ & $40(17.4 \%)$ \\
\hline 3 & I am afraid that if I do not come to work I will lose my job. & $19(8.7 \%)$ & $30(13 \%)$ & $77(33.5 \%)$ & $63(27.4 \%)$ & $41(17.8 \%)$ \\
\hline 4 & I will not report for duty because I am afraid of falling ill. & $9(3.9 \%)$ & $25(10.9 \%)$ & $67(29.1 \%)$ & $74(32.2 \%)$ & $55(23.9 \%)$ \\
\hline 5 & $\begin{array}{l}\text { I will not report for duty because I am afraid of spreading } \\
\text { the disease to my family and friends }\end{array}$ & $12(5.2 \%)$ & $26(11.3 \%)$ & $59(25.7 \%)$ & $75(32.6 \%)$ & $58(25 \%)$ \\
\hline
\end{tabular}

The above table shows that though majority of respondents accepted that the risk of getting infection as part of their job (38.3\% agree and $18.7 \%$ strongly agree), there were still significant proportion of respondents who were either unsure $(29.9 \%)$ or unwilling (11.3\%agree, and $3.9 \%$ strongly agree with statement).

The research also looked at the willingness of healthcare workers to report for duty during disasters and emergencies. The respondents were asked the question: "If you were not on duty and were asked to come to work because the hospital 
has had a large number of casualties to take care of as a result of a disaster, would you be willing to do so?" One hundred thirty five $(58.7 \%)$ of the respondents would be willing to report for a call in times when hospital encounters mass casualty as result of disaster. The specialists had the highest proportion $(100 \%)$ of respondents followed by Residents (71.4\%) who would be willing to do so. While significant proportion $(16.5 \%)$ of the staff were not willing to come to work during a mass casualty as result of disasters, $24.8 \%$ were not sure whether or not they would come. Only $23.8 \%$ of respondents who were designated as "administrations" would be willing to work during disaster. Of those who would not be willing to work, pharmacists account higher proportion $(36.4 \%)$. Staffs those who were not willing to report for duty had to indicate reasons of unwillingness. The common reasons respondents provided were: "I am not sure on how I am going to approach a disaster incident; the hospital might not care for me; and the disaster may be frustrating".

\subsection{Practice of the Respondents on Disaster Preparedness at the Hospital}

This study generally showed low practice of disaster preparedness at Tikur Anbessa hospital. This was evidenced as the study obtained only $19(8.3 \%)$ of practice score.

Disaster drills and simulation exercise at the hospital: The emergency preparedness process needs a system of continuous monitoring and evaluation with the intent checking capability of one's facility and closing the identified gaps. According to the key informants, the hospital conducted its first disaster drills that involved up to 200 patients two years back. The informants remarked that the hospital would have not been failed to sustain this promising beginning. The informants further noted that it was important to conduct drills and simulation exercise to test whether the system was prepared or not. The respondents were also asked whether their hospital had conducted drills or not. The results are shown in table 9 below.

Table 9. Practice of disaster on drills and training or education related to disaster preparedness at the hospital, Addis Ababa, Ethiopia, 2013.

\begin{tabular}{lllll}
\hline 1 & Does the hospital conduct disaster drills or simulation exercises regarding disaster situation? & $24(10.5 \%)$ & $91(39.6 \%)$ & $115(50 \%)$ \\
2 & Does the hospital conduct training/workshops to educate staff members about disasters? & $29(12.6 \%)$ & $79(34.3 \%)$ & $122(53 \%)$ \\
\hline
\end{tabular}

Training, workshops and education: From the key informant interviews it was noted that there has not been any formal training or workshops conducted for hospital staffs in terms of the management of emergencies and disasters. This was noted by the respondents who filled in the questionnaire. Only $29(12.6 \%)$ of them indicated that the hospital had conducted workshops/training, while 122(53\%) did not know and $79(34.6 \%)$ indicated that the hospital had not conducted workshops/training. The key informants, on the other hand, mentioned that they fully believe in the importance of training and workshops in getting ready for disaster. This study found that only $9.1 \%$ of them attended workshops/training. None of the administration indicated that they attended workshops. Most of the staffs (94.5\%) had not participated in the development or reviewing of the hospital disaster plan. The only experience of the hospital was preparation of a patchy disaster plan entitled "Triaging Mass Casualty" in 2010. Though its sustainability was not ensured, the document could help the hospital conduct a simulation exercise which was the first in its type. From then on wards, neither simulation exercise nor disaster drill was conducted at the hospital.

\section{Discussion}

Disasters are a health and a social issue. Damage to health care systems affects every part of society and nations as a whole. Literatures reveal that the incidence of disasters and the cost they demand have increased for years both because of development processes and because of lack of development. This fact is certainly the reflection of the current situation in Ethiopia. In other words, the country is in fact showing impressive changes in socio-political and economic aspects; it is yet not wealthy enough to with stand impacts of a disaster.

The continued occurrence and magnitude of disasters prompted WHO and other organizations to come up with best practice models for hospitals. This resulted in increased attention on healthcare disaster preparedness and response in research agendas. Over the years, there have been efforts by WHO and other technical bodies in promoting hospital preparedness, examples being the 2008-9 world disaster reduction campaign with a goal of "hospitals safe from disasters" and more recently the 2010-11 "one million safe schools and hospitals" initiative [3].

In this study, about half $(50.8 \%)$ of the health care workers at Tikur Anbessa specialized hospital had good knowledge about hospital disaster preparedness and its plan. Evidences reveal that many people think of a disaster as 'routine accident' or events which cannot be anticipated. With this in consideration, this study has tried to find out the view of the study participants and found that around $2 / 3^{\text {rd }}$ of the respondents mentioned that they knew the term 'disaster' while about $13.7 \%$ of them did not know it. To make sure that those who said they knew the term correctly knew it, the checking question presented was whether external assistance after an occurrence of a disaster is needed or not. Sixty one $(26.5 \%)$ of them was not sure whether or not external assistance is needed disaster incidents. Around $4.8 \%$ respondents were wrongly perceived the term as they refused to accept the need of external assistance aftermath of a disaster. Such perception results in a focus on responding to the immediate needs created by a disaster rather than preventing or reducing effects.

Most experts in the field of emergency management agree that the primary source of information for the general public about disasters is the mass media (Fisher, 1996) [27]. A recent workshop held by the African Union brought together 
member state representatives and journalists to discuss the importance of the media and ways to use the media to raise awareness about disasters and improve community resilience in their aftermath [34]. In this study, half (50\%) of respondents had received information about disaster from books. Lesser proportions $(16 \%, 12 \%$, and $10 \%)$ respectively mentioned their source of information to be television, radio, and others sources. Study by Mangala, showed, 63.3\%, $16.7 \%$, and $6.7 \%$, and $8.3 \%$ of the study participants had respectively received information about disaster from television, radio, journals, and other sources [35]. The observed difference could certainly be as a result of difference in media involvement at the study areas.

The awareness of disaster plan components is essential to manage disaster as effectively and efficiently. In this study, $52.2 \%$ of the respondents did not know what a hospital disaster plan should contain. Similar study in Namibia on Onandjokwe Lutheran hospital showed most of (70.3\%) respondents did not know components of hospital disaster plan [28].

Role of hospital in disasters may extend far beyond direct lifesaving, as they are also symbols of social progress and economic development (ISDR, 2008). Inadequate knowledge on role of hospital could lead to role confusion during disaster incidents. This study however, found that significant proportion $(52.2 \%)$ were not aware what roles are expected from themselves and the hospital during disasters. Study by Carley and Mackway-Jones in British showed that only 54\% of respondents felt confident in the knowledge of their specific role during a major incident [17]. In survey by WHO to assess health sector emergency preparedness in member states at regional and global level (WHO/HAC, 2008:3) participants reported the lack of a dedicated emergency preparedness and response unit within the ministry of health [18]. In this study, respondents favor presence of disaster policy in health care system. This can be summarized by the quote of one of the key informants as: "The presence of such a policy could affect many things; it affects management, budgeting, equipment and supply; it also entails accountability and responsibility. It generally affects the whole system of health care organization".

Disaster researches demonstrate staffs that perform most efficiently are those of performing relatively familiar tasks. Previous exposure of disasters may influence how effectively and efficiently health professional handle disaster victims [27]. This study found that about $42 \%$ of respondents rated their knowledge and skill of handling disasters as poor. Similar study in Namibia found around $20 \%$ of the respondents rated their knowledge and skill as poor [28]. The deviation could be probably because Namibia had formally written disaster plan and periodic disaster drill which is no present in Ethiopia.

Concerning the level of disaster preparedness, this study found that the hospital was poorly prepared. One important element in the maintenance of a high level of preparedness is the maintenance of adequate staff that is knowledgeable and capable of responding to disasters. The survey conducted by
WHO confirmed lack of human resources in emergency preparedness found to impede the development of emergency preparedness policies and program $(27,29)$. This study found lack of awareness as main the factor that hampers disaster preparedness at the hospital. This is in line with the survey conducted in South Africa that concluded lack of awareness as possible challenge to disaster management preparedness [27]. Negligence and lack of previous exposure to disasters were observed to be the other the possible factors that lagged hospital disaster preparedness. Extensive survey of the literatures found that the greater the frequency that communities experience disasters, the more extensive will be their disaster planning efforts [25]. According to literatures, the public attitude toward disasters is often a mixture of "what happen will happen" and "It cannot happen here". People living in high-risk areas accept the threat philosophically ("earthquakes come with the territory") (Drabek, 1986:320, 340) [23]. In this stud, greater proportions of respondents were aware that the hospital could be affected by disasters. The finding, thus, implicates that the healthcare workers were aware of the hazards that surrounded them, and they were aware that those hazards could affect the hospital.

The rationale behind this finding was realizing the suggestions forwarded by Chaffe and Oster (2006:37) as "hospital emergency preparedness can be enhanced by a advocating the philosophy "Imagining the unimaginable" [34]. According to the German sociologist Ulrich Beck (1992), we live in a "risk society" [35]. With the intention of identifying what possible hazards were particularly likely to occur in and or around the hospital, this study found that fire/lightening, structural collapse, and disease outbreak were among the main fear at the area. Unusual conditions like terrorist attack and earth quakes were also speculated to occur in or around the hospital.

Following lack of dedicated emergency preparedness and response unit within the ministry of health of many countries, WHO called for many countries' ministry of health to participate in emergency preparedness and response as independent wing in health service system [8]. This study revealed that separate health sector disaster policy that enables all hospital to have clear disaster plan should be incorporated in health care planning. Almost all of the study participants strongly recommended the ministry of health to prepare a policy that motivates all hospitals to have disaster plan. This can be summarized by the quote of one of them key informant: "The presence of such a policy could affect many things; it affects management, budgeting, equipment and supply; it also entails accountability and responsibility; it, generally, affects the whole system of health care organization".

Training and education in disaster preparedness are considered as back bone. One study conducted to evaluate the effectiveness of an emergency preparedness training program for public health staff in China showed that emergency preparedness training was found to improve the knowledge levels and increased attitudinal and behavioral 
intention scores for emergency preparedness [18]. In this study, however, only $9.1 \%$ of them attended workshops/training related to disasters/emergencies.

In disaster planning, the willingness to respond for duty during an occurrence of a disaster is a critical issue [32]. This research looked at the willingness of healthcare workers to report for duty during disasters and emergencies and found that majorities $(95.6 \%)$ of the respondents indicated that they would be willing to do so. Significant numbers of staffs $(16.5 \%)$, nevertheless, said that they would not report if call by the hospital during disaster incident. This is in line with a study by Barnett et al. (2009) about attitudes and beliefs toward emergency response among local public health communities that found $16 \%$ of the workers were not willing to respond to a pandemic flue emergency [22]. Common reasons mentioned in this study not to be willing include: "I am not sure on how I am going to approach a disaster", the hospital might not care for me", and "the disaster may be so frustrating

Simulation exercises and disaster drills are tools to test the capacity of a facility. They also help familiarize health care workers with how to and what to do in real situations of disasters. At this study area however, simulation exercise was conducted only once in history of the hospital. Study done by Abhinav (2008) uncovered that adequacy of knowledge and practice, and portraying positive attitude is driven by being involved in disaster response and attending disaster-related practical educations [33].

\section{Conclusion and Recommendation}

The effective means of reducing the tragedies of disasters is by anticipating, mitigating, preparing for, responding to, and recovering from them. As hospitals are among the most important institutions in disaster response, they should be prepared and need to have preparedness plan. This study concluded that the hospital was lagged far behind on disaster preparedness. It has neither identified disaster risk profiles nor comprehensive disaster plan. There was even no clear guide line on patient evacuation systems and no arrangement at all was in place on where to displace the patients should the hospital encounters disaster calamity. Considerable number of the hospital's staffs had not even clearly known role of hospital and that themselves in times of disasters strike. Despite their favorable attitude towards disaster preparedness, they were not sure about what to do and how to approach disaster events. The country's ministry of health should formulate health sector "all hazards" and "whole health" approach disaster preparedness policies and legislation. Hospitals throughout the country should be alert and ready for possible calamity of disasters. Training human power and incorporating disaster management in education curricula is highly recommended.

\section{Acknowledgements}

We would like to take this opportunity to first of all thank
God for allowing us to live to this day. Next, we thank Addis Ababa University for financial support.

\section{References}

[1] Principles of Disaster Mitigation in Health Facilities, edition. $4^{\text {th }}$, vol. 2, pp. 7-21.

[2] World Health Organization (WHO). (2007b). Mass Casualty Management Systems: Strategies and guidelines for building health sector capacity. Geneva, Switzerland: WHO.

[3] Ala A, Health Action in Crises World Health Organization, World Disaster Campaign 2008-2009, "Hospitals Safe from Disaster", available at www.unisdr.org /wdrc-2008-2009.

[4] Karen M, In Case of Emergency - Hospital Staff Need Proper Preparation for Potential Disasters Vol. 12 No 7 P. 42.

[5] World Bank and Global Facility for Disaster Reduction and Recovery, November 2010 vol.2, pp. 79-103 available at http://www.cred.be/sites/default/files/ADSR_2011.pdf

[6] Anne E, Literature and best practice review and assessment: Identifying people's needs in major emergencies and best practice in humanitarian response: available from www.unisdr org. uk/public/reports/60-1.

[7] Hyogo Framework for Action 2005-2015: Building the Resilience of Nations and Communities to Disasters available at www.unisdr.org/wcdr

[8] World Health Organization Regional Office for Africa (WHOAFRO). (s.a.). Emergency and Humanitarian Action (EHA): Overview. Retrieved May 15, 2011, from WHO-AFRO: http://www.afro.who.int

[9] World Bank and Global Facility for Disaster Reduction and Recovery, November 2012 at http://www.cred.be/sites/default/files/ADSR.

[10] Facility for Disaster Reduction and Recovery (GFDRR) Secretariat, "Management Programs for Priority Countries", November 2009, Web site: www.gfdrr.org

[11] Lukamba Y, Natural disasters in African countries: what can we learn about them? TD The Journal for Tran disciplinary Research in Southern Africa, 6(2) December 2010, pp. 478-495.

[12] World Health Organization, Health Action in Crises, Ethiopian Strategy Paper, May 2005, pp 1-7.

[13] Lynn A. Slepski T. Pilot study result, Disaster Management \& Response, Volume 5, Issue 4, pages 99-110.

[14] Sahdeo, Joanne URI: http://hdl.handle.net/10539/6935, Prehospital and Disaster Medicine / Volume 23, Issue01/ February 2008, pp 63-67 DOI, http://dx.doi.org/10.1017/S1049023X00005598 (About DOI), Published online: 28 June 2012.

[15] Collander B, Green B, Millo Y, Shamloo C, Donnellan J, DeAtley C: Development of an "all-hazards" hospital disaster preparedness training course utilizing multi-modality teaching. Prehospital Disast Med 2008; 23(1).

[16] Prizzia R, Helfind G, Emergency Preparedness and disaster Management in Hawaii, Case study, 2004, available from http://www.emeraldinsight.com/insight/view Content Servle 
[17] Wong K, Turner PS, Boppana A, Nugent Z, Coltman T, Cosker TD, Blagg SE. Preparedness for the next major incident: are we ready? 1: Emerg Med J. 2006 Sep; 23(9):70912).

[18] Leiba A, Drayman N, Amsalem Y, Aran A, Weiss G, Leiba R, Schwartz D, Levy Y, Goldberg A, Bar-Dayan Y. Establishing a high level of knowledge regarding bioterrorist threats in emergency department physicians: methodology and the results of a national bio-preparedness project. 1: Prehosp. Disaster Med. 2007 May-Jun; 22(3):207-11, discussion 2123.

[19] Chongjian W, Sheng Wei, Hao X, Yihua X, Shenghong H, Ommari B, Mkangara, Shaofa N, Evaluating the effectiveness of an emergency preparedness training programme for public health staff in China, (2008 ), vol. 122, 471-477.

[20] Fung OW, Loke AY, Lai CK. Disaster preparedness among Hong Kong nurses. 1: J Adv Nurs. June 2008, 62(6):698-703.

[21] J. Williams, M. Nocera, C. Casteel. The Effectiveness of Disaster Training for Health Care Workers: A Systemic Review, Annuals of Emergency Medicine, Vol 52, Issue 3 Pages 211-222.

[22] American Society of Public Health. Retrieved February 22, 2009 from American Society of Public Health Web site: http//www.asph.org/cphp/CPHP_ResourceReport.cfm.

[23] Dewi H, S. Kep. Ns Urai H, Aranya Ch, Nurses' Preparedness of Knowledge and Skills in Caring for patients attacked by Tsunami in Indonesia and its relating factors,2010, vol. 3, pp $5-10$.

[24] Low - Cost Measures to Improve Local Emergency Preparedness and Response in New Jersey June 2011, pp 1012.

[25] Academic Medicine, Preparing Health Professions Students for Terrorism, Disaster, and Public Health Emergencies: Core Competencies, Vol. 80, No. 6 / June 2005, pp 515-526.
[26] Abhinav Sinha, D. K. Pal, P. K. Kasar, R. Tiwari, A. Sharma, (2008) "Knowledge, attitude and practice of disaster preparedness and mitigation among medical students", Vol. 17 Issue: 4, pp. 503-507.

[27] Rosemary M, knowledge, attitudes and practices of health care workers regarding disaster preparedness at Johannesburg hospital in Gauteng province, south Africa, November 2008, vol. 1, pp. 33-39.

[28] Gerald N. Hospital Emergency and Disaster Preparedness: a study of Onandjokwe Lutheran hospital, northern Namibia, 2011, Vol. 1, pp. 80-91.

[29] Belinda W, Disaster preparedness in the United States, 2008, vol. 1, pp. 16-28.

[30] Spranger C, Villegas D, Kazda M, Harris A, Mathew S, Migala W, Assessment of Physician Preparedness and Response Capacity to bioterrorism or other Public Health Emergency events in a Major Metropolitan Area., Volume 5, Issue 3, Pages 82-86.

[31] Government of India- United Nations Development Programme (GOI/UNDP). Guidelines for Hospital Emergency Preparedness Planning, India: UNDP.

[32] Welzel, T. B., Koenig, K. L., Bey, T. \& Visser, E. (2010). Effect of Staff Surge Capacity on Preparedness for a Conventional Mass Casualty Event. Western Journal of Emergency Medicine, 11 (2), 189-196.

[33] Abhinav Sinha, D. K. Pal, P. K. Kasar, R. Tiwari, A. Sharma, (2008) "Knowledge, attitude and practice of disaster preparedness and mitigation among medical students", Disaster Prevention and Management, Vol. 17 Iss: 4, pp. 503507.

[34] Chaffe, M. W. \& Oster, N. S. (2006). The Role of Hospitals in Disasters. In G. R. Ciottone, P. D. Anderson, I. Jacoby, E. A. Der Heide, E. Noji, R. G. Darling, et al. (eds.), Disaster Medicine (3rd ed., pp. 34-42). Philadelphia: Mosby Elsevier. 